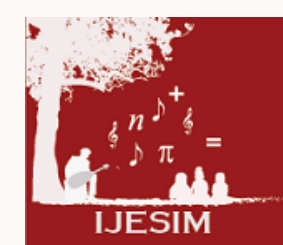

International Journal of Educational Studies in Mathematics

ISSN: 2148-5984

wWw.ijesim.com

\title{
Effectiveness of an Online Manipulative Tool and Students' Technology Acceptances
}

\author{
Serkan Ozel ${ }^{1}$, Zeynep Ebrar Yetkiner Ozel ${ }^{2}$, Lauren D. Cifuentes ${ }^{3}$
}

${ }^{1}$ Department of Primary Education, Bogazici University, Istanbul, TURKEY

${ }^{2}$ Department of Elementary Education, Fatih University, Istanbul, TURKEY

${ }^{3}$ Office of Distance Education and Learning Technologies, Texas AEM - Corpus Christi, USA

\section{ABSTRACT}

\begin{abstract}
Given strong research support for improvement of students' conceptual understanding with multiple representations, it is important to understand effects of different representations on student achievement. In this study, an online manipulative tool (OMT) was introduced to students to support their study of rational number operations. The purpose is to compare different representational aspects of OMT and to estimate OMT's effects on achievement and technology acceptance when compared to traditional classroom activities. Elementary- and middle-grade students were randomly assigned to the control group $(\mathrm{N}=14)$ or one of the following three treatment groups: (a) audiovisual $(\mathrm{N}=14)$, (b) virtual-kinesthetic $(\mathrm{N}=15)$, and (c) dual-mode (virtual-kinesthetic and audiovisual combined) groups $(\mathrm{N}=11)$. When the control group was compared with experimental groups, pre- and post-test results suggested OMT was more effective than traditional classroom activities in improving students' understanding of rational number operations. When students' achievement on pre- and post-tests among experimental groups was compared, no substantial difference was found. However, students in the dual-mode group scored the highest on technology acceptance survey. The results suggest learning can be facilitated by virtual manipulatives. However, students' acceptances of technology should be considered when implementing new technologies.
\end{abstract}

Keywords:

Online manipulative tool, Technology acceptance, Rational numbers, Multiple representations, Mathematics education

(C) 2014 IJESIM. All rights reserved

Article History:

Received 18.02.2014 Received in revised form 10.04.2014 Accepted 01.05.2014 Available online 01.06.2014

\section{Introduction}

This study reports on the effects of an online manipulative tool (OMT) that included different modes of representations on students' understanding of operations with rational numbers - comparison, addition, subtraction, and multiplication. In addition, students' beliefs about OMT's usefulness and their acceptances of the newly introduced technology were investigated. The study also compared students' achievement on OMT-based assessments versus achievement on traditional paper-and-pencil assessments. Previous research on OMTs has established the importance of such tools on students' mathematics achievement (e.g., Reimer \& Moyer, 2005; Suh\& Moyer, 2007; Suh, Moyer, \&Heo, 2005). Research also showed students built positive

${ }^{1}$ Corresponding author's address:Department of Primary Education, Bogazici University, Istanbul, TURKEY, 34342

Telephone:+(90) 2123596592

Fax: +(90) 2123597032

e-mail: ozels@boun.edu.tr

DOI: http://dx.doi.org/10.17278/ijesim.2014.01.001

Authors' Note: This paper is an extended version of a conference paper that appeared as Ozel \&Yetkiner (2010). The key additions of this journal version are as follows: First, literature review is extended to analyze the relationship between the related literature and the purpose of the current paper. Second, an additional research question is added to answer another important aspect of the online tool developed for this study. Finally, discussion is extended to add value to the paper. 
attitudes toward mathematics when they used OMTs in their mathematics classrooms (Moyer, Niezgoda, \& Stanley, 2005; Reimer \& Moyer, 2005; Steen, Brooks, \&Lyon, 2006; Suh\& Moyer, 2007; Suh et al., 2005).

\section{Same Concept, Different Representations}

Research in mathematics education has demonstrated effectiveness of multiple modes of representations in helping students develop conceptual understanding (e.g., Ainsworth, 2006; Amato, 2008; Fennell \& Rowan, 2001; Gagatsis \& Elia, 2004; Perry \& Atkins, 2002; Suh et al., 2005). Multiple modes facilitate different perspectives on a particular concept thereby scaffolding deeper understanding (Ainsworth, Bibby, \& Wood, 1997). For example, presenting a fraction as a linear model on a fraction strip helps students build the concept of fraction as a number; whereas, an area model emphasizes the numerator and denominator of a fraction in relation to partioning a whole. Dienes (1973) argued presenting the same concept with various representations helped students build abstract mathematical thinking. When students are exposed to symbolic or concrete representations of mathematical concepts prior to learning formal mathematical notations, they can link the concrete representations with abstract mathematical ideas. Thus, integrating various representations combines the strength and eliminates the weakness of any single representation (Elia, Gagatsis, \& Demetriou, 2007).

Selecting appropriate representations is an important consideration for effective instruction because different representations have varying degrees of effects on teaching and learning (Duval, 2002). Although some representations may provide similar information, each representation can have different loads on students' cognitive resources (Larkin \& Simon, 1987). For example, the cognitive load of understanding a diagram can be more than the cognitive resources needed when the diagram is accompanied with textual information physically linked to related segments of the diagram. The explanatory textual information can help students with mental integration of information and ease the recognition and understanding of the diagram.

Not only individual representations do have different impacts on students' conceptual understanding but also integrating multiple representations may have interaction effects. Research has indicated that interaction among representational modes supports students' conceptual understanding (Elia et al., 2007); however, this interaction may hinder learning if representations are not chosen and integrated carefully (Mayer, 2005; Sweller, van Merrienboer, \& Paas, 1998). Elia et al. (2007) found students had more difficulties solving problems presented with informational pictures as compared to problems presented in verbal mode. Students who were given problems with informational pictures had to combine the information presented in text with the picture, thus, splitting their attention between both the pictorial and verbal representations. This allocation of cognitive resources into several processes was indicated to reduce effectiveness in information processing. Given unfavorable results of ineffective integration of various representations into instruction, Sweller et al. (1998) proposed instructional design principles for presenting information in different modes.

Split-attention effect, one of Sweller et al.'s (1998) instructional design principles, helps to reduce cognitive load by physically integrating different sources of information in the instructional design in order to lower learners' needs of mental integration. For example, let us think of a learner who is trying to learn how to use software by reading a manual. This learner needs to read the manual first and then apply his or her reading to the software. Thus, the process causes the learner to split the attention between reading the manual and then applying it to the software. In order to reduce cognitive load, instructions could be read to the learner while the learner practices with the software. In this latter case, the information in the manual is integrated in the software as audio. This integration reduces the cognitive load by letting the learner focus on the software while listening to the instructions.

Another instructional design principle suggested by Sweller et al. (1998) was the modality effect. This principle suggests incorporating visual and auditory components together to increase the capacity of working memory and decrease the cognitive load (Sorden, 2005). In his review of research on the modality effect principle, Mayer (2005) presented an example of a modality effect: Students who received instruction as oral-narration and graphics performed better than students who received instruction as on-screen text and graphics. The oral-narration-and-graphics group could use both auditory and visual channels; whereas, the 
on-screen-text-and-graphics group's visual channel suffered from being overloaded with two types of visual information.

\section{Beliefs and Attitudes}

Students' beliefs and attitudes toward mathematics and instructional strategies can affect students' achievement (DeBellis \& Goldin, 1993; McLeod, 1992). Goldin (2000) conjectured possible relationships between affective states of students' feelings and students' problem-solving heuristics. Moreover, Goldin (2000) inferred how these affective representations can improve or inhibit mathematical problem solving skills. For example, frustration during problem solving may prevent a student from pursuing the solution or, on the contrary, motivate the student to find the solution.

Research on physical manipulatives showed that students had higher mathematics achievement and better attitudes toward mathematics when physical manipulatives were implemented into instruction (Sowell, 1989). Because of virtual manipulatives' additional features to facilitate teaching and learning of mathematics, one would expect virtual manipulatives help students improve their achievement in mathematics as well as enhance their attitudes toward mathematics. Indeed, research, which was mainly done with kindergarten and elementary school students, also showed gains both in mathematics achievement and attitudes when virtual manipulatives were used (Moyer et al., 2005; Reimer \& Moyer, 2005; Steen et al., 2006; Suh \& Moyer, 2007; Suh et al., 2005).

Virtual manipulatives offer important learning characteristics favored by students (Reimer \& Moyer, 2005; Suh et al. 2005). Reimer and Moyer (2005) found students preferred virtual manipulatives over traditional activities because virtual manipulatives could provide immediate and specific feedback. This feature of virtual manipulatives enhanced students' attitude toward mathematics by providing a safe learning environment where students could learn from their own mistakes (Reimer \& Moyer, 2005; Suh\& Moyer, 2007; Suh et al., 2005). Additionally, in this safe learning environment students could use their creativity more wisely than on paper-and-pencil activities (Moyer et al., 2005). Students could flexibly create patterns, freely test their ideas with virtual manipulatives, and share these ideas and their mathematical thinking with others.

Despite the aforementioned advantageous features of virtual manipulatives, students' perceptions of virtual manipulatives are an important mediating factor in the effect of these features on students' achievement. When students are presented with a new technology such as virtual manipulatives, students need to accept the new technology in order to derive its advantages (Ching, 1999). If students do not accept a new technology, it is most likely that either students will not use the new technology or the technology will not be beneficial for students' learning. Therefore, it is important to emphasize technology acceptance in classrooms when implementing a new technology.

Davis (1989) developed the Technology Acceptance Model (TAM) to explain and predict acceptance behaviors and usage intentions of a new technology. TAM includes three constructs: perceived usefulness, perceived ease of use, and enjoyment. A student's belief that the new technology will enhance his or her achievement is called perceived usefulness (Davis, 1989). In order for students to use a technological tool, they should believe the tool will enhance their performance. Perceived ease of use, on the other hand, is the belief that the new technology will be free of effort (Davis, 1989). Perceived ease of use, through its relationship to perceived usefulness, as reflected in the user friendliness of a new technology is also an important factor in technology's perceived usefulness (Yi \& Hwang, 2003). If a user struggles with the tool, then the difficulties encountered can affect the perceived usefulness. According to Yi and Hwang (2003) enjoyment is an external factor that influences perceived ease of use. Davis (1989) defined enjoyment as the extent to which a student found the tool enjoyable. Vrielink (2008) argued learning took place when students accepted a technology, thus, students' perceptions of the technological tool would affect students' performances.

TAM has been used widely to explore how technology acceptance is related to user backgrounds (e.g., gender or ethnicity) as well as different technologies or tasks (King \& He, 2006). However, studies on technology acceptance were mostly conducted with adult participants, sometimes with college students, and very rarely with k-12 students. Because technology acceptance is paramount for actually using the 
technology (Lee, Kozar, \& Larsen, 2003), it is important to understand the factors that are related to K-12 students' technology acceptances. Previous research suggested the differential use of technology in the schools is related to the achievement gap between different ethnicities (e.g., Kirby \& Styron, 1994). In addition to ethnicity, some studies indicated that differences in the extent to which technology is used in classrooms were related to gender (Selby \& Ryba, 1993). Although the gender-based difference in technology use is narrowing, male students reported using technology more frequently than their female peers (Miller, Schweingruber, \& Brandenburg, 2001). Information about inequities in technology acceptance due to student characteristics can provide insights about the aforementioned differential use of technology in classrooms.

\section{Assessment: The Crossroad Between Teaching and Learning}

Assessment is a continuing process that measures a learner's performance and progress toward establishing learning outcomes and that provides feedback to improve learning (Center for Teaching, Learning, and Assessment, n.d.). Wiliam (2008) described this ongoing process as a bridge between teaching and learning and suggested assessment should be learning oriented. Peltenburg, van den Heuvel-Panhuizen, and Doig(2009) argued learning-oriented assessments can be designed in interactive learning environments.

A learning-oriented assessment can be embedded into an instructional design (Wiliam, 2008), and this type of assessment is called dynamic assessment (Peltenburg et al., 2009). Dynamic assessment takes place during the learning process rather than at the end of the learning as in traditional assessments. Thus, dynamic assessment is more effective than a traditional assessment model in identifying learner's ability orreasons for failure (Lidz, 1991). In traditional assessments students need to show their performance without any feedback or manipulatives. However, dynamic assessments evaluate students' performances on learning tasks as they interact with the learning environment (Peltenburg et al., 2009). In particular, low performing students can benefit the most from dynamic assessment (Allsopp et al., 2008).

Interactive environments with embedded dynamic assessment can evaluate students' progress and provide immediate and specific feedback with no apparent assessment. Virtual manipulatives, in particular, can be programmed to track students' progress and provide hints and feedback accordingly (Reimer \& Moyer, 2005; Suh \& Moyer, 2007; Suh et al., 2005). These hints and feedback provide support and engage students in problem-solving processes and help students adjust their mathematical thoughts (Wiliam, 2008). The freedom offered to students by virtual manipulatives to experiment their ideas can facilitate successful performance. Thus, the embedded assessment within virtual manipulatives not only does measure students' progress but also scaffolds their learning.

\section{Research Questions}

Given strong research support for improvement of students' conceptual understanding with multiple representations (e.g., Ainsworth, 2006; Amato, 2008; Fennell \& Rowan, 2001; Gagatsis \& Elia, 2004; Perry \& Atkins, 2002; Suh et al., 2005), it was important to understand the effect of different modes of representations on student achievement. Using multiple representations via technology to present rational number concepts could provide evidence for understanding the relationship between the representational mode used and achievement (cf. Martin \& Schwartz, 2005). In addition, students' beliefs and attitudes toward mathematics and instructional strategies can affect students' achievement (DeBellis \& Goldin, 1993; McLeod, 1992). Therefore, it was essential to know how students' beliefs and attitudes toward OMT changed over time and how beliefs and attitudes were related to students' characteristics and representational modes. Students perform better and reveal their hidden competences when assessment is embedded in instruction (i.e., invisible assessment) (Peltenburg et al., 2009). Because OMT yielded invisible assessment information, there was an opportunity to investigate the relationship between scores received on OMT and paper-based tests.

Five major questions guided this study:

1. What is the impact of the OMT on students' understandings of operations with rational numbers? How does the impact of the OMT on achievement differ by the representational mode (i.e., audiovisual, virtual-kinesthetic, and dual-mode)? 
2. Do students' beliefs and attitudes toward usefulness of OMT change over time as they experience OMT?

3. Are there differences in technology acceptances of (a) boys and girls and (b) students with different SES as measured by TAM-M?

4. Is there a difference in students' technology acceptances by the representational mode (i.e., audiovisual, virtual-kinesthetic, and dual mode) as measured by TAM-M?

5. How do students perform on OMT compared to traditional paper-and-pencil tests?

\section{Method}

\section{Design}

The experimental design was intended to compare OMT's different aspects and to estimate effects of OMT over traditional classroom activities. Elementary- and middle-grade students from fourth, fifth, seventh, and eighth grades participated in the study. The students were randomly assigned to the control group $(N=14)$ or one of the following three treatment groups: (a) audiovisual $(N=14),(b)$ virtual-kinesthetic $(N=15)$, and (c) dual-mode (virtual-kinesthetic and audiovisual components combined) $(N=11)$. Random assignment was performed within each grade separately in order to avoid over assignment to any group in each grade.

\section{Participants}

Fifty-four elementary- and middle-grade students in five classes at a college preparatory charter school participated in the study. The school was located in the state of Texas. Fourth, seventh, and eighth grades were represented with one class, and fifth grade was represented with two classes. Table 1 presents participants' demographic information.

Table 1. Sample Demographics

\begin{tabular}{|c|c|c|c|}
\hline Grade & \multicolumn{2}{|c|}{ Gender } & $n$ \\
\hline & Female & Male & \\
\hline 4 & $42 \%$ & $58 \%$ & 14 \\
\hline 5 & $40 \%$ & $60 \%$ & 20 \\
\hline 7 & $91 \%$ & $9 \%$ & 11 \\
\hline 8 & $45 \%$ & $55 \%$ & 11 \\
\hline Overall & $52 \%$ & $48 \%$ & 54 \\
\hline
\end{tabular}

Note. Percentages may not add up $100 \%$ because of rounding.

\section{Procedure}

Students in the experimental groups used OMT for six sessions, each 30-minute long, over 2 weeks. The participating classes remained intact throughout the study. In other words, even though students were randomly assigned to different groups (i.e., three experimental and one control) in each classroom, students within a classroom participated in the study together and within their classroom periods. The study was conducted in a spring semester.

All students participated in direct instruction delivered by their teacher. After instruction on the fraction concepts was over, students in experimental groups engaged in additional activities with OMT. The control group did not receive any treatment other than teacher-assigned activities. Teacher-assigned activities were from textbooks by Holt, Rinehart and Winston or Pearson. 


\section{Online Manipulative Tool}

The online manipulative tool (OMT) was interactive Internet-based computer software designed to present students with problems on addition, subtraction, multiplication, and comparison of rational numbers. For each comparison problem, fractions were less than one. For addition, subtraction, and multiplication problems, fractions and results were equal to or less than one.

The software differed among experimental groups based on the representational mode used while providing the same content. The audiovisual group watched an instructional video on operations with rational numbers with virtual manipulatives, whereas the virtual kinesthetic group actively used virtual manipulatives to solve rational number questions. The dual-mode group was provided with the opportunity to use virtual manipulatives as the virtual-kinesthetic group and to watch the same instructional videos given to audiovisual group as they wished.

The OMT consisted of two virtual manipulatives: (a) virtual fraction strips and (b) a virtual area board. Virtual fraction strips presented students with comparison of rational numbers in a similar manner to physical fraction strips. The virtual area board provided an interactive environment where students could use an area model to add, subtract, and multiply rational numbers. A screen shot of the virtual fraction strips and the virtual area board can be seen in Figure 1.
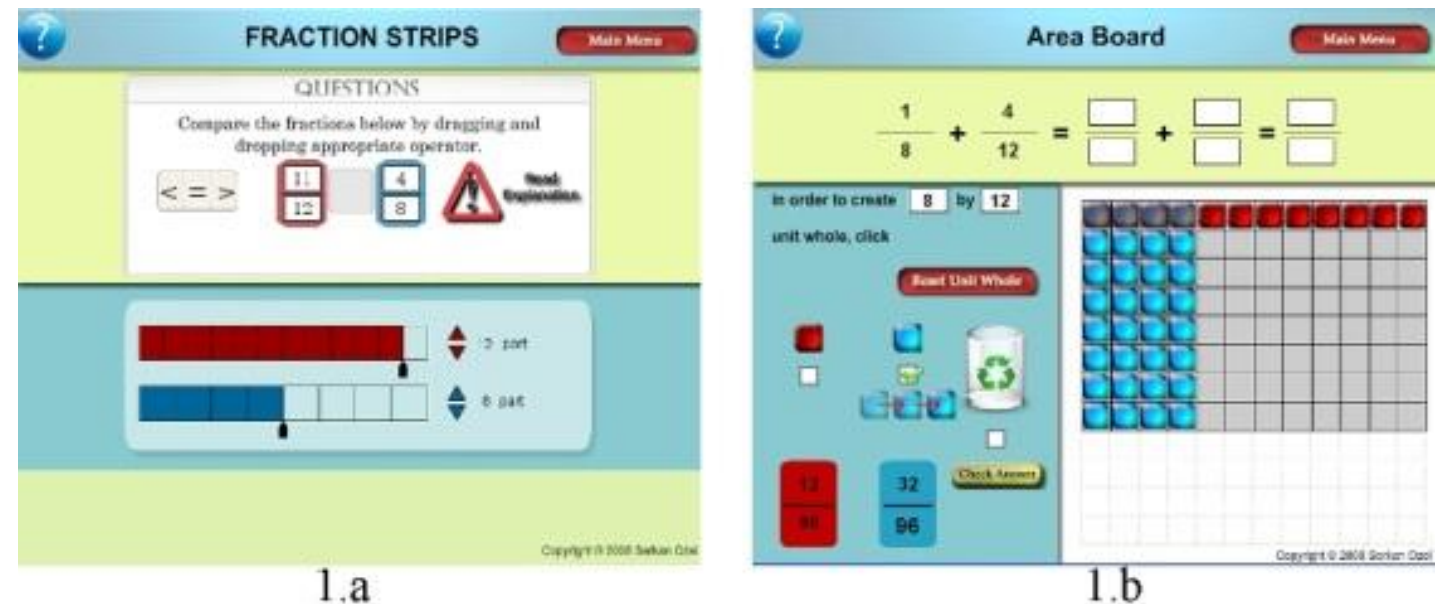

Figure 1. Screenshots of virtual fraction strips and area board.

The tool employed several research protocols to improve the quality of the data collected. The OMT coded the content on the screen every 5 seconds. The coded information on the screen included every click, the question being solved, current progress on manipulatives, the final solution in both algorithm and manipulative representations, and the feedback provided for students' answers. The purpose of screen coding was to provide precise information about students' progress to ensure a complete accounting of each attempt. Additional protocols to ensure data dependability and reliability were collection of data regarding the total time spent on each item and the Internet protocol (IP) address.

\section{Measures}

Students were administered a pre- and a post-paper-and-pencil test on addition, subtraction, multiplication, and comparison of rational numbers. Students were not allowed to use the OMT during the paper-and-pencil tests. Two versions of both pre- and post-tests were administered: versions A of the preand post-tests to fourth and fifth grades and versions B of the pre- and post-tests to seventh and eighth grades. Although the content and structure were the same on both versions, the difficulty level was higher on versions B. Each version consisted of 10 items on rational number operations investigating students' algorithmic and representational skills. Pre- and post-tests were evaluated using a rubric that had a score range of $0-19$. 
To investigate students' perspectives on the usefulness of OMT as they studied operations with rational numbers, an after-software questionnaire (ASQ) was adapted from Vrielink (2006). The ASQ was a four-item 5 -point Likert-type questionnaire $(1=$ strongly disagree to $5=$ strongly agree $)$. The ASQ was administered to experimental groups at the end of every other session. That is, students completed ASQ three times throughout the study. The Cronbach's alpha reliability estimates for the first, second, and third administrations of ASQ were $.95, .94$, and .96 , respectively.

At the end of the study, students in experimental groups were administered the Technology Acceptance Model Modified (TAM-M) questionnaire adapted from Vrielink (2006). The original TAM was developed by Davis (1989) for adults. The TAM-M version was validated for students between ages 12 and 17 (Vrielink, 2006) and contained an 11-item 5-point Likert-type questionnaire $(1=$ strongly disagree to $5=$ strongly agree $)$. The questionnaire addressed three constructs: (a) enjoyment, (b) ease of use, and (c) usefulness. The Cronbach's alpha reliability estimate for the whole TAM-M questionnaire was .96. For each construct the Cronbach's alpha reliabilities were as follows: .90 for ease of use, .91 for usefulness, and .91 for enjoyment.

\section{Data Analysis}

For the first research question, to determine the impact of the OMT on students' understanding of operations with rational numbers, gain scores from pre to post paper-and-pencil tests were compared across control and experimental groups. First, gain scores were calculated as the arithmetic difference between post- and pre-tests. Subsequently, 95\% confidence intervals (CIs) were constructed around each group's gain scores. CIs allowed for the comparison of control and experimental groups' achievement as well as comparisons of three experimental groups' achievement to one another.

For the second research question, to determine students' perspectives about usefulness of OMT over time, confidence intervals (CIs) around means were calculated for each administration of ASQ. In addition, CIs around means for each ASQ administration were investigated by experimental group (i.e., audiovisual, virtual-kinesthetic, and dual mode). CIs allowed for the examination of the change in students' beliefs and attitudes toward OMT within each experimental group and across groups.

For the third and fourth research questions, differences in students' technology acceptance levels (as measured with TAM-M) by sex, SES, and representational mode were discussed using CIs and box-plots, which allowed for comparisons of distributions side-by-side.

For the last research question, students were divided into two groups based on their posttest scores on the paper-and-pencil test: Students who scored below 9 out of the maximum possible score of 19 were grouped as low performers, and students who scored at or above 9 were grouped as high performers. Then, performances of the low and high performers on OMT during the last session were compared using CIs. The performances on OMT were evaluated both on algebraic notation and on kinesthetic representation. Scores on algebraic notation and on kinesthetic representation were obtained as the ratio of the number of correct answers to the total number of items attempted.

\section{Results}

Research Question 1. CIs around the gain scores for each group are presented in Figure 2. There were recognizable differences between the control group and each of the experimental groups with the following Cohen's $d$ effect sizes: .59 for the difference between the control $(M=.79, S D=5.0)$ and the audiovisual groups $(M=3.38, S D=3.73), .47$ between the control and the virtual-kinesthetic groups $(M=2.90, S D=3.78)$, and .68 between the control and the dual-mode groups $(M=3.82, S D=3.66)$. These results suggested OMT were more effective than traditional classroom activities in improving students' understanding of operations with rational numbers. CIs also allowed us to compare gain scores across the experimental groups. No apparent differences were observed in experimental groups' achievement by the representational mode (see Figure 2). 


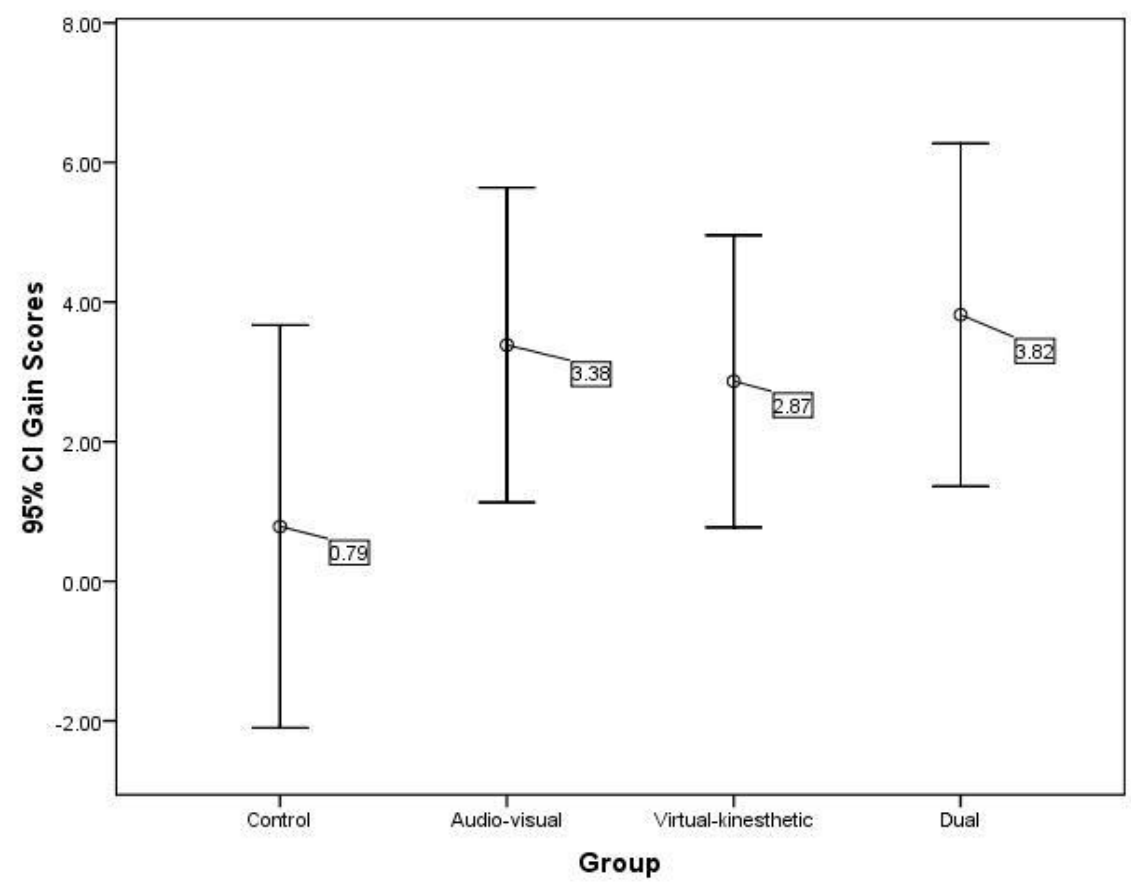

Figure 2. 95\% CIs around gain scores for each group.

Research Question 2: CIs around the means are given in Figure 3. Mean scores on ASQ steadily increased across administrations. The Cohen's $d$ effect size for the mean difference between the third $(M=$ $13.08, S D=5.10)$ and the first administrations $(M=11.25, S D=4.74)$ was 0.4 . Figure 4 presents a more detailed comparison of ASQ scores within each experimental group and across groups. There is an increasing trend in the means in the dual-mode group; whereas, means for the audiovisual and virtual-kinesthetic groups were relatively stable across administrations. A recognizable finding was the dual-mode group's mean score was below the means of other groups in the first administration and above the means of all other groups in the last administration. The Cohen's $d$ effect size for the increase in the mean of the dual-mode group from the first $(M=9.54, S D=5.22)$ to the last administration $(M=14.27, S D=6.40)$ was 0.8 .

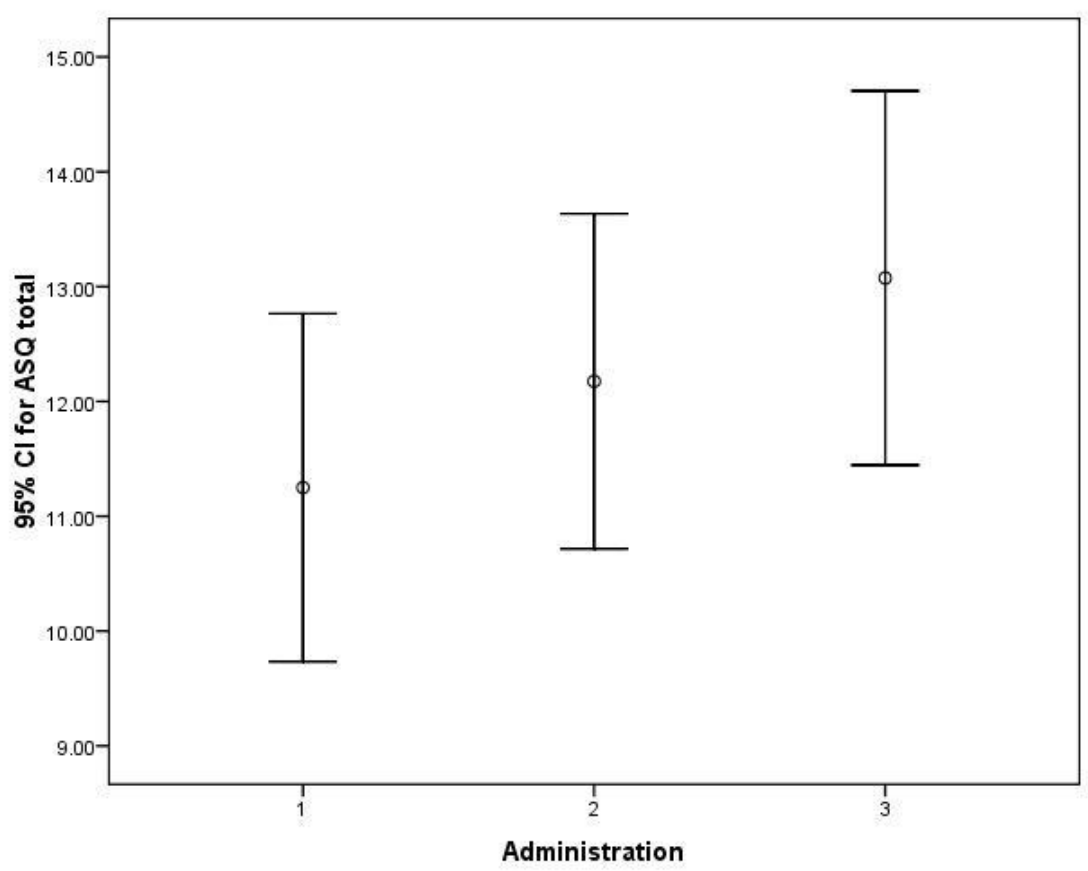

Figure 3. CIs around means for each administration of ASQ. 


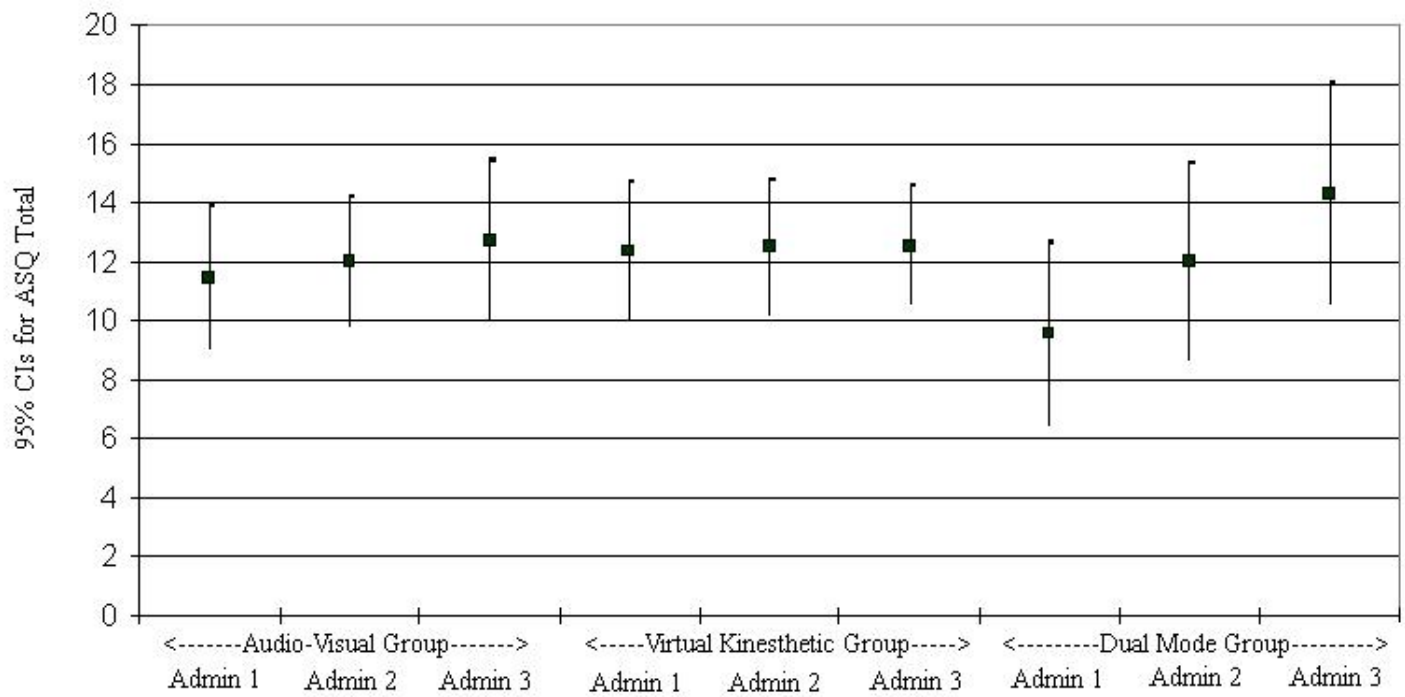

Figure 4. CIs around ASQ means byadministration and group.

Research Question 3: Figure 5 displays score distributions of boys and girls on TAM-M with box-plots. Gray areas in Figure 5 represent 95\% CIs around means, and means are represented with diamonds. As conveyed by the box-plots, score distributions for boys and girls on TAM-M were similar although the variation was a little higher for girls. Also CIs in Figure 5 suggested no difference between boys' and girls' technology acceptances.

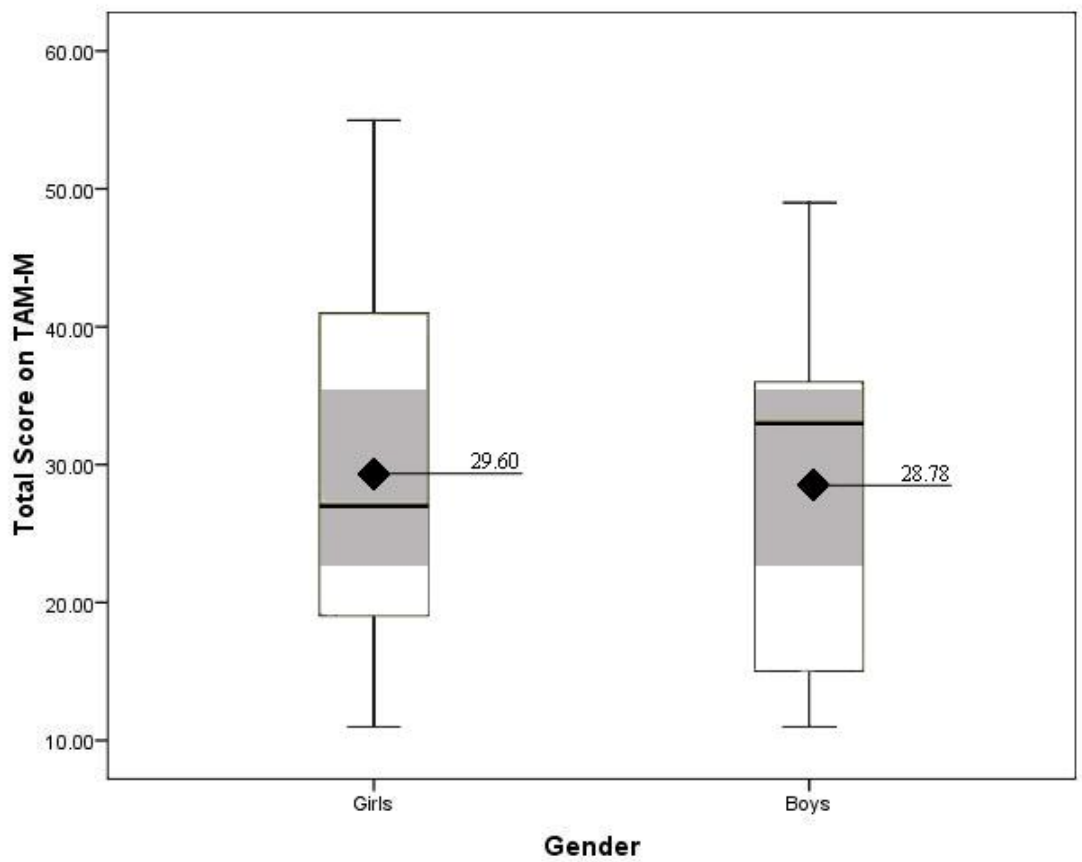

Figure 5. Total scores on TAM-M by gender displayed with box plots and 95\% CIs.

Distributions of total scores on TAM-M by SES are displayed with box-plots in Figure 6. On average students with low SES scored higher than students with high SES. In fact, approximately $50 \%$ of students with low SES got scores comparable to high SES students in the upper quartile. Gray areas in Figure 6 represent $\mathrm{CIs}$ around means, which are denoted by diamonds. The CIs also indicated statistically significant difference between students with low $(M=32.47, S D=13.45)$ and high SES $(M=24.53, S D=11.20)$ in their average score on TAM-M (Cohen's $d=.62)$. 


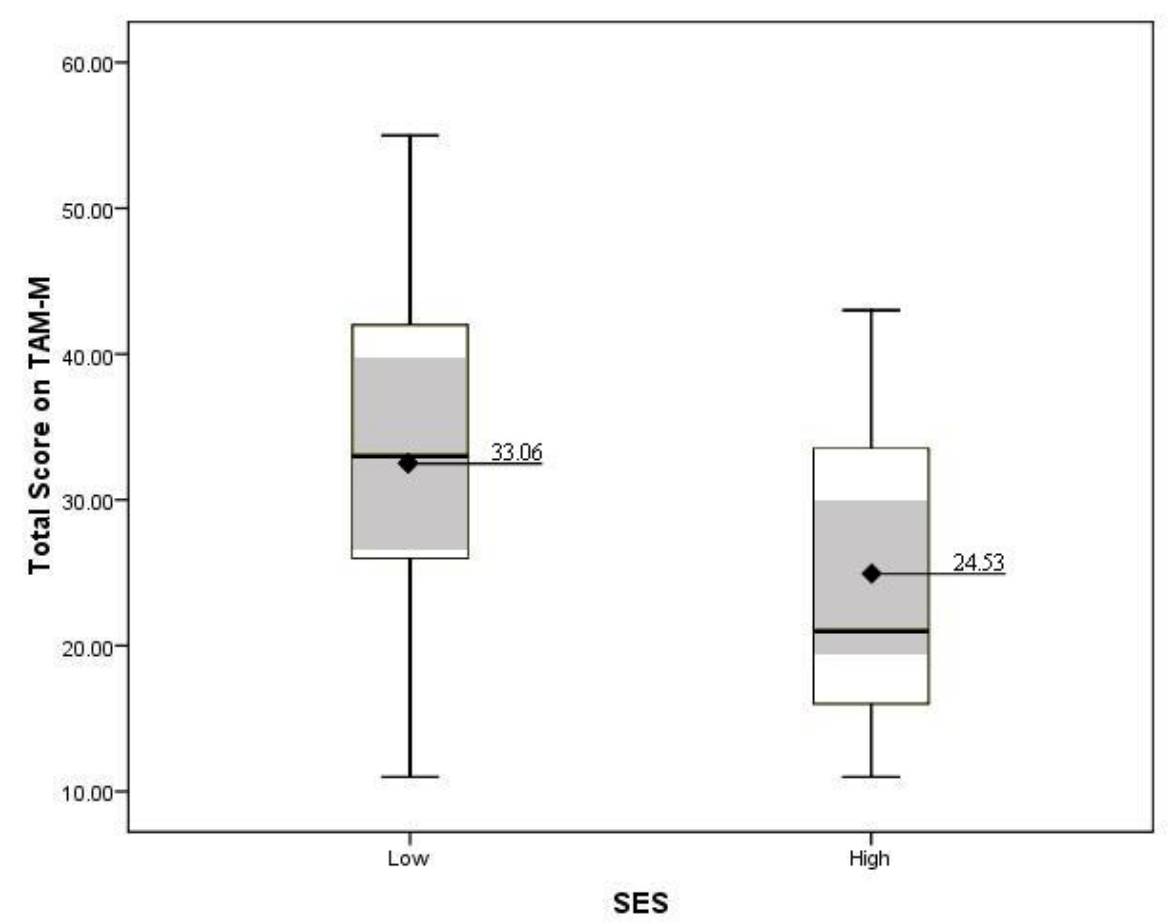

Figure 6. Total scores on TAM-M by SES levels displayed with box plots and 95\% CIs.

Research Question 4: Figure 7 displays score distributions of each experimental group on TAM-M with box-plots. Gray areas in represent $95 \%$ CIs around means, and means are represented with diamonds. The audiovisual group's average TAM-M score was lower than that of virtual-kinesthetic and dual-mode groups. Further, more than $50 \%$ of the students in the dual-mode group had scores comparable to the scores in the upper quartile of both audiovisual and virtual-kinesthetic groups.

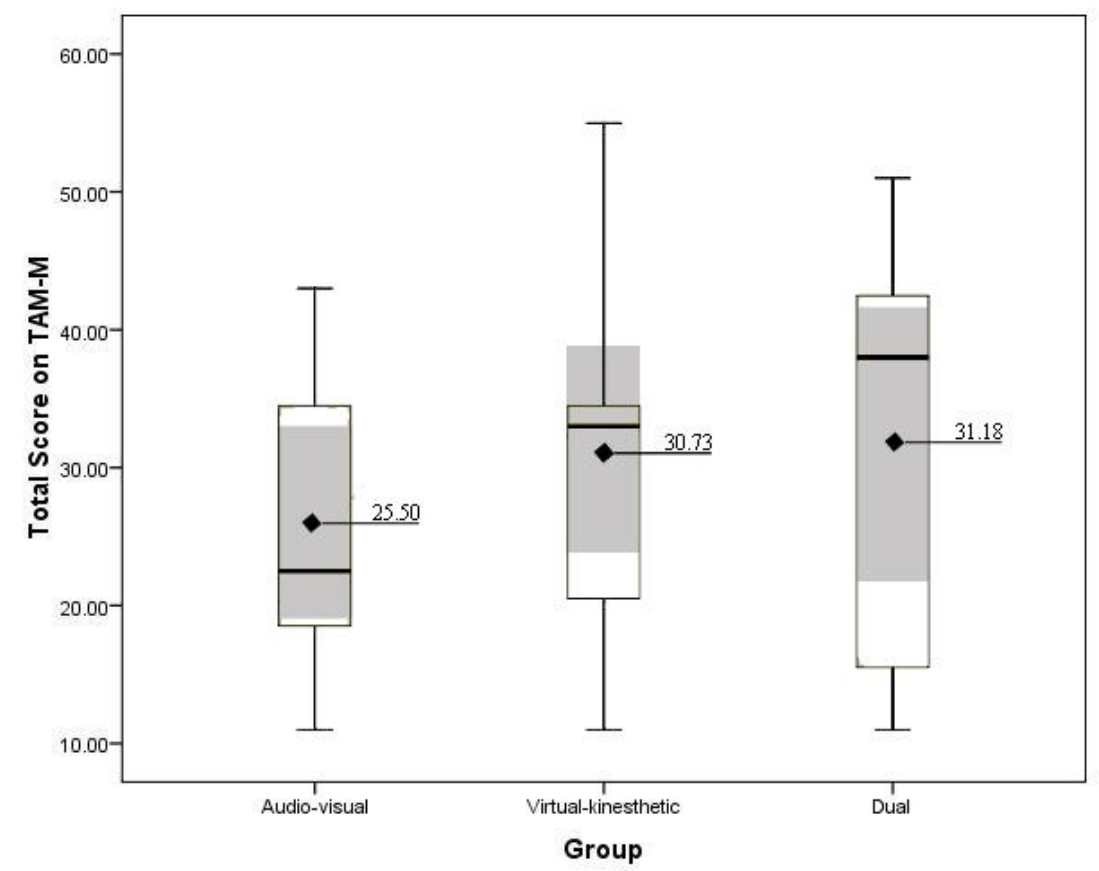

Figure 7. Total scores on TAM-M by group displayed with box plots and 95\% CIs. 


\section{Research Question 5:}

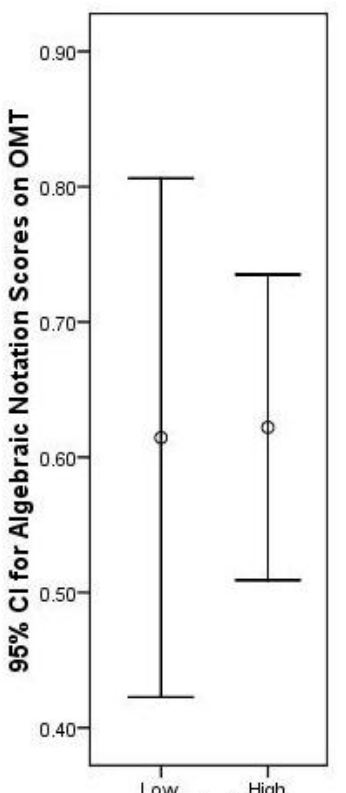

(a)

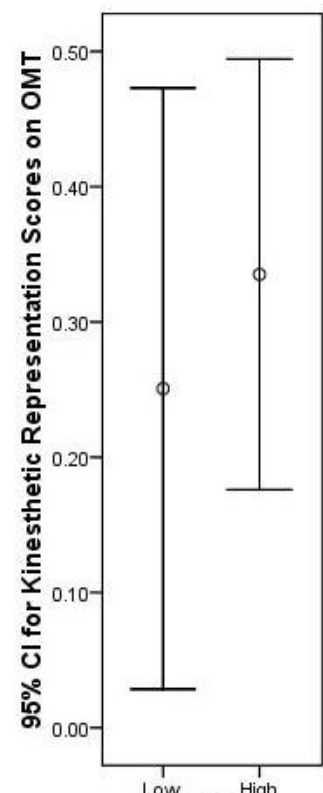

(b)

Low versus High Performers on the Posttest

Figure 8. Comparison of low and high performers on algebraic notation (a) and kinesthetic representation (b) scores on OMT using 95\% CIs.

As seen in Figure 8, on neither the algebraic notation nor the kinesthetic representation scores on OMT are there differences between the low and high performers (see Figure 8a and 8b). The average scores of low and high performers both on OMT algebraic notations and kinesthetic representations are similar although the variation in the low performers is higher.

\section{Discussion and Conclusion}

In the current study, students who used the OMT achieved better than students who attended teacherassigned classroom activities. Students who used the OMT received activities in different representational modes including audiovisual, kinesthetic, or both audiovisual and kinesthetic. On the other hand, students in the control group were provided with textbook activities. Our finding suggested each representational mode provided different affordances that could not be found in traditional classroom activities such as move-ability, draw-ability, feedback, and focus-ability affordances in manipulatives and watch-ability, playback-ability, focus-ability, and highlight-ability in audio-video representation. Each affordance in video and manipulative provided students with opportunity to watch (video) or manipulate (manipulative) the transitioning from concrete representation to the symbolic mode. Students could use these affordances to process the information and give meaning to them to transfer into long-term memory. Moreover, they could retrieve this information to succeed on the paper-and-pencil test. This finding supports current literature on the effectiveness of teaching and learning fractions with online learning tools (Reimer \& Moyer, 2005; Suh \& Moyer, 2007).

When gain scores on achievement among experimental groups were compared, there was no difference among experimental groups. Representational modes in experimental groups were dynamic and interactive in nature. Students in the audiovisual group were presented with rational numbers concepts in a dynamic 
media; whereas, students in the virtual-kinesthetic group used interactive online manipulatives. On the other hand, students in the dual-mode group were provided with both the dynamic media and interactive online manipulatives to choose from. Hypothetically, one would expect students who use interactive online manipulatives achieve better than the students who watch a dynamic media because interactive online manipulatives provide students with the opportunity to manipulate objects, to dynamically see changes in different modes, and to receive immediate and specific feedback for their solution strategies. However, no difference based on representational mode was found in this study (see Figure 2). This finding suggested different representational modes resulted in similar performance via different affordances. Students could meaningfully encode information into their long-term memory and retrieve it efficiently using their cognitive resources. This result is aligned with Kaput's (2006) and Bolyard and Moyer-Packenham's (2006) findings that dynamic video and interactive manipulative has similar effects on students conceptual understanding of mathematics.

Students' perspectives on the usefulness of the OMT increased over time. One of the hypotheses for this finding was that because students had not used virtual manipulatives before, initially they might have had difficulties in understanding how the manipulatives worked. This hypothesis is supported by the previous research concluding that if users do not have difficulties when using a technology, they are more likely to perceive that particular technology more useful (Yi \& Hwang, 2003). This hypothesis also supports the more positive change in students' perceptions of usefulness of the OMT in the dual-mode group as compared to the virtual-kinesthetic group. The dynamic video in the dual-mode group scaffolded students' manipulative skills. When these students had difficulties using manipulatives, they could easily switch to the videos where they could learn how to use manipulatives as well as about operations with rational numbers.

In the current study, boys' and girls' technology acceptances did not differ. This finding is in accordance with current research indicating the gap between male and female students' technology uses is narrowing (Hargittai \& Shafer, 2006; Ono \& Zavodny, 2003). However, students' technology acceptances differed among different SES groups. More specifically students from low SES families had higher acceptance levels compared to students from high SES families. Students from higher income families have been found to use computers in school and at their homes more frequently than students from lower-income families (Becker, 2001; Coley, Cradler, \& Engel, 1997). One can conclude that the mechanism of SES (i.e., parent literacy, parental help, accessibility to resources/materials) might have an influence on students' perceptions of technology. Because the low SES group might have not experienced such tools before, they could have been more open to the tool when they were first introduced. On the other hand, high-SES students could have had access to different technologies (iPods, computers at home, etc.) so they were not very excited about the tool.

Students' TAM-M scores in experimental groups showed that almost $50 \%$ of the students in both the virtual-kinesthetic and dual-mode groups scored similar to the students in the upper quartile of the audiovisual group. Thus, most of the students who used virtual manipulatives (either in the virtualkinesthetic or dual-mode groups) had better perceptions of OMT. Because virtual manipulatives were common in both groups, these results suggest students enjoyed using virtual manipulatives and found them more useful than the dynamic video component because they could create their own models and express their creativities on them. This conclusion supports previous research by Moyer et al. (2005), who also concluded virtual manipulatives promote students' creativity. Moreover, even though students in the virtual-kinesthetic and dual-mode groups had similar mean TAM-M scores, more than half of the students in the dual-mode group scored higher on TAM-M than three quarters of students in the virtual-kinesthetic group. The dynamic video component in the dual-mode group could have had an effect on the easiness of OMT and resulted in better technology acceptance. The video could have supported students when they had difficulties using virtual manipulatives, thereby helping them feel more comfortable using the newly introduced virtual manipulatives.

Because students took both paper-and-pencil tests and OMT-based assessments, this study allowed us to compare students' achievement on these two types of assessment. When students' scores on OMT were analyzed based on their paper-based post-test scores, there was no difference on either students' algebraic scores or students' kinesthetic representation scores between low and high performers. Low-performing students on the paper-based test showed their competence on not only kinesthetic representations but also 
algebraic notations on OMT. This result signifies the importance of the embedded dynamic assessment taking place during the learning process. It is apparent that lower-performing students achieved better in a learning oriented dynamic assessment than a paper-based test. The OMT scaffolded students to reveal their hidden competencies. This finding is in accordance with Allsopp et al. (2008) who concluded lowperforming students could benefit the most from dynamic assessments.

This study has important implications for teaching and learning practice as well as for instructional design. Online learning tools such as dynamic video and interactive manipulatives improve students' conceptual understanding of mathematics. Thus, teachers should consider incorporating such tools in their classrooms. However, students' acceptance of such tools depends on their perceived ease of use so instructional designers should develop user-friendly interfaces for online learning environments. When utilizing a learning tool in their classrooms, teachers need to provide students with enough time to spend on learning the tool so that students would encounter fewer difficulties. In addition, teachers and instructional designers should pay special attention to affordances of media provided with online learning tools because additional affordances incorporated in virtual manipulatives were more acceptable by students.

\section{References}

Ainsworth, S. (2006). DeFT: A conceptual framework for considering learning with multiple representations. Learning and Instruction, 16, 183-198.

Ainsworth, S., Bibby, P., \& Wood, D.J. (August, 1997). Evaluating principles for multi-representational learning environments. Paper presented at the seventh European Association for Research on Learning and Instruction, Athens, Greece.

Allsopp, D. H., Kyger, M. M., Lovin, L., Gerretson, H., Carson, K. L., \& Ray, S. (2008). Mathematics dynamic assessment: Informal assessment that responds to the needs of struggling learners in mathematics. Teaching Exceptional Children, 40(3), 6-16.

Amato, S. A. (2008). The use of relational games in initial teacher education: Bringing the classroom into the lecture theatre. In B. Clarke, B. Grevholm, \& R. Millman (Eds.), Tasks in primary mathematics teacher education: Purpose, use, and exemplars (pp. 177-196). New York, NY: Springer.

Becker, H. J. (April, 2001). How are teachers using computers in instruction? Paper presented at the American Educational Research Association, Seattle, WA.

Bolyard, J., \& Moyer-Packenham, P. S. (2006). The impact of virtual manipulatives on student achievement in integer and addition. In S. Alatorre, J. L. Cortina, M. Saiz, \& A. Mendez (Eds.), Proceedings of the twenty-eighth annual meeting of the North American Chapter of the International Group for the Psychology of Mathematics Education (pp. 879-881). Merida, Mexico: Universidad PedagogicaNacional.

Center for Teaching, Learning, and Assessment (n.d.). What is assessment? Retrieved August 1, 2011, from http://nwhealth.edu/ctl/asmnt/whatis.html

Ching, O. (1999). Assessment of staff attitudes towards computers and its implications on the use of IT in school. Suntec City, Singapore: Ministry of Education.

Coley, R. J., Cradler, J., \& Engel P. K. (1997). Computers and classrooms: The status of technology in schools, Princeton, NJ: Policy Information Center-Educational Testing Service.

Davis, F. D. (1989). Perceived usefulness, perceived ease of use, and user acceptance of information technology. MIS Quarterly, 13, 319-340.

DeBellis, V. A., \& Goldin, G. A. (1993). Analysis of interactions between affect and cognition in elementary school children during problem solving. In J. R. Becker \& B. J Pence (Eds.), Proceedings of the fifteenth 
annual meeting of PME-NA, Vol. 2 (pp. 56-62). Pacific Grove, CA: Center for Mathematics and Computer Science Education, San Jose State University.

Dienes, Z. P. (1973). The six stages in the process of learning mathematics. Slough, UK: NFER-Nelson.

Duval, R. (2002). The cognitive analysis of problems of comprehension in the learning of mathematics. Mediterranean Journal for Research in Mathematics Education, 1(2), 1-16.

Elia, I., Gagatsis, A., \& Demetriou, A. (2007). The effects of different modes of representation on the solution of one-step additive problems. Learning and Instruction, 17, 658-672.

Fennell, F., \& Rowan, T. (2001). Representation: An important process for teaching and learning mathematics. Teaching Children Mathematics, 7, 288-292.

Gagatsis, A., \& Elia, I. (2004). The effects of different modes of representation on mathematical problem solving. In M. J. Høines\& A. B. Fuglestad (Eds.), Thetwenty-eighth conference of the InternationalGroup for the Psychology of Mathematics Education: Vol. 2. (pp. 447-454). Bergen, Norway: Bergen University.

Goldin, G. A. (2000). Affective pathways and representation in mathematical problem solving. Mathematical Thinking and Learning, 2, 209-219.

Hargittai, E., \& Shafer, S. (2006). Differences in actual and perceived online skills: The role of gender. Social Science Quarterly, 87, 432-448.

Kaput, J. J. (2006). Technology and mathematics education. In D. A. Grouws (Ed.), Handbook of research on mathematics teaching and learning: A project of the National Council of Teachers of Mathematics (pp. 515556). Reston, VA: National Council of Teachers of Mathematics.

King, W. R., \& He, J. (2006). A meta-analysis of the technology acceptance model. Information \& Management, $43,740-755$.

Kirby, P. C., \& Styron, R. (1994). Inequities in school computer use. The Journal of At Risk Issues, 1(2), 13-17.

Larkin, J. H., \& Simon, H. A. (1987). Why a diagram is (sometimes) worth more than ten thousand words. Cognitive Science, 11, 65-99.

Lee, Y., Kozar, K. A., \& Larsen, K. R. T. (2003). The technology acceptance model: Past, present, and future. Communications of the Association for Information Systems, 12, 757-780.

Lidz, C. S. (1991). Practitioner's guide to dynamic assessment. New York, NY: Guilford.

Martin, T., \& Schwartz, D. L. (2005). Physically distributed learning: Adapting and reinterpreting physical environments in the development of fraction concepts. Cognitive Science, 29, 587-625.

Mayer, R. E. (2005). Principles for reducing extraneous processing in multi-media learning: Coherence, signaling, redundancy, spatial contiguity, and temporal contiguity. In R. E. Mayer (Ed.), The Cambridge handbook of multi-media learning (pp. 183-200). New York, NY: Cambridge University Press.

McLeod, D. B. (1992). Research on affect in mathematics education: A reconceptualization. In D. A. Grouws (Ed.), Handbook of research on mathematics teaching and learning (pp. 575-596). New York, NY: Macmillan.

Miller, L. M., Schweingruber, H., \& Brandenburg, C. L. (2001). Middle school students' technology practices and preferences: Re-examining gender differences. Journal of Educational Multimedia and Hypermedia, 10, 125-140.

Moyer, P. S., Niezgoda, D., \& Stanley, J. (2005). Young children's use of virtual manipulatives and other forms of mathematical representations. In W. J. Masalaski\& P. C. Elliott (Eds.), Technology-supported mathematics learning environments (pp. 17-34). Reston, VA: National Council of Teachers of Mathematics.

Ono, H., \& Zavodny, M. (2003). Gender and the internet. Social Science Quarterly, 84, 111-121. 
Özel, S., \& Yetkiner, Z. E. (2010). Multiple representation perspective and students' acceptance of an online manipulative tool. In J. Sanchez \& K. Zhang (Eds.), Proceedings of E-Learn 2010 (2671-2680). Chesapeake, VA: Association for the Advancement of Computing in Education.

Peltenburg, M., van den Heuvel-Panhuizen, \& Doig, B. (2009). Mathematical power of special-needs pupils: An ICT-based dynamic assessment format to reveal weak pupils' learning potential. British Journal of Educational Technology, 40, 273-284.

Perry, J. A., \& Atkins, S. L. (2002). It's not just notation: Valuing children's representations. Teaching Children Mathematics, 9, 196-201.

Reimer, K., \& Moyer, P.S. (2005). Third-graders learn about fractions using virtual manipulatives: A classroom study. Journal of Computers in Mathematics and Science Teaching, 42, 5-25.

Selby, L., \& Ryba, K. (1993). Creating gender equitable computer learning environments. Journal on Computing in Teacher Education, 10(2), 7-10.

Sorden, S. D., (2005). A cognitive approach to instructional design for multimedia learning. Informing Science Journal, 8, 263-279.

Sowell, E. J. (1989). Effects of manipulative materials in mathematics instruction. Journal for Research in Mathematics Education, 20, 498-505.

Steen, K., Brooks, D., \& Lyon, T. (2006). The impact of virtual manipulatives on first grade geometry instruction and learning. Journal of Computers in Mathematics and Science Teaching, 25, 373-391.

Suh, J., \& Moyer, P. S. (2007). Developing students' representational fluency using virtual and physical algebra balances. Journal of Computers in Mathematics and Science Teaching, 26, 155-173.

Suh, J., Moyer, P. S., \& Heo, H. (2005). Examining technology uses in the classroom: Developing fraction sense using virtual manipulative concept tutorials. Journal of Interactive Online Learning, 3(4), 1-21.

Sweller, J., van Merrienboer, J. J. G., \& Paas, F. G. W. C. (1998). Cognitive architecture and instructional design. Educational Psychology Review, 10, 251-296.

Vrielink, R. (2006). Predicting the use of Blackboard and predicting the use of a personal digital analyser with the technology acceptance model: A comparative and cross-validation among Dutch pupils aged 12-18. Current Developments in Technology-Assisted Education, 1, 591-595.

Vrielink, R. (April, 2008). An empirical investigation of students' acceptance of Web-based technology. Paper presented at the fourth ELMAC Conference, Sheffield, UK.

Wiliam, D. (August, 2008). When is assessment learning-oriented? Paper presented at the fourth biennial EARLI/Northumbria Assessment Conference, Potsdam, Germany.

Yi, M. Y., \& Hwang, Y. (2003). Predicting the use of web-bases information systems: Self-efficacy, enjoyment, learning goal orientation, and technology acceptance model. International Journal of Human-Computer Studies, 59, 431-449. 